\title{
UNDERSTANDING UNCERTAINTIES IN FUTURE COLORADO RIVER STREAMFLOW
}

\author{
by Julle A. Vano, Bradley Udall, Daniel R. Cayan, Jonathan T. Overpeck, Levi D. Brekke, \\ tapash Das, Holly C. Hartmann, Hugo G. Hidalgo, Martin Hoerling, Gregory J. McCabe, \\ Kiyomi Morino, Robert S. Webb, Kevin Werner, and Dennis P. Lettenmaier
}

A synthesis of studies on Colorado River streamflow projections that examines methodological and model differences and their implications for water management.

$\mathrm{T}$ he Colorado River is the primary water source for more than 30 million people in seven rapidly growing, mostly arid American states and Mexico. The Colorado River water supply system, which consists of two large reservoirs (Lakes Mead and Powell) and numerous smaller reservoirs, is already stressed because of growing water demand and an ongoing drought that is outside the historical norm of twentieth-century climate variability (Fulp 2005; USBR 2011a). Concerns have been voiced that this recent prolonged drought could be a harbinger of a permanent shift to a drier climate (Seager et al. 2007; Barnett and Pierce 2008, 2009; Overpeck and Udall 2010; Cayan et al. 2010; USBR 2011a, among others).

Numerous studies of the Colorado River basin's hydroclimate provide evidence for increased drying, although each study (Fig. 1; Table 1) has its own

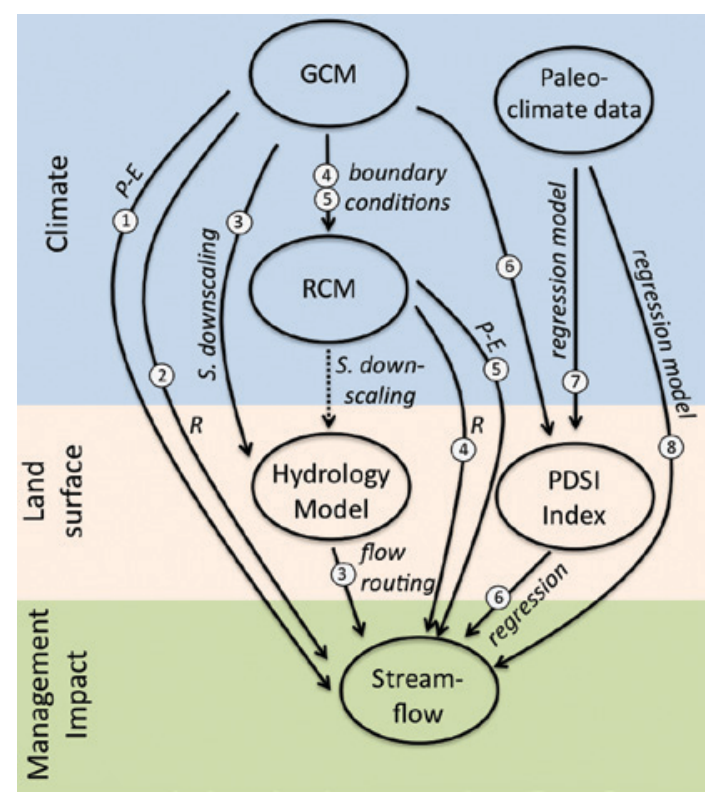

Studies using various approaches:

1. Seager et al. 2007; Seager et al. 2013

2. Milly et al. 2005

3. Christensen et al. 2004; Christensen and Lettenmaier, 2007; Cayan et al. 2010; USBR 2011a

4. Gao et al. 2011; Rasmussen et al. 2011

5. Gao et al. 2012

6. Hoerling and Eischeid 2007

7. Cook et al. 2004

8. Woodhouse et al. 2006; McCabe and Wolock 2007; Meko et al. 2007; USBR 2011a

Abbreviations:

GCM - Global Climate Model

RCM - Regional Climate Model

PDSI - Palmer Drought Severity Index

$\mathrm{P}$-Precipitation

$\mathrm{T}$ - Temperature

R-Runoff

E - Evaporation

S. downscaling - statistical downscaling

FIG. I. Approaches to generating future projections. Dotted lines indicate possible future studies. Land surface models (LSMs) are often incorporated into GCMs and RCMs, or they can be run (usually after downscaling) offline, in which case they use output from climate models (e.g., precipitation, temperature, wind speed) and essentially serve as macroscale hydrology models. Paleoclimate data can also be used to evaluate and improve how GCMs simulate historical climate. 
unique approach and results. Seager et al. (2007, p. 1181) summarize global climate model (GCM) results for the western United States, which they state indicate that "this region [the southwestern United States] will dry in the 21st century and that the transition to a more arid climate should already be under way." These results, when extracted for the Colorado River basin, which we do in comparisons below, show reductions in runoff of approximately $19 \%$ by the mid-twenty-first century, although Seager and Vecchi (2010) subsequently argued for the need for higher-resolution modeling to better represent the role of complex topography of the Colorado River headwaters in future climate projections. Other studies using offline simulation methods also indicate drying with magnitudes of runoff decline that vary widely from as little as 6\% (Christensen and Lettenmaier 2007, hereafter C\&L) to as much as $45 \%$ (Hoerling and Eischeid 2007) by midcentury.

Despite indications of consensus of climate models regarding future drying (e.g., NRC 2011), there is still considerable variability in future climate projections-for instance, one-third of 112 future climate projections from a set of Intergovernmental Panel on Climate Change (IPCC) Fourth Assessment Report (AR4) phase 3 of the Coupled Model Intercomparison Project (CMIP3) GCM projections investigated by the USBR (2011a) show no change or increases in Colorado River streamflow, a number that varies depending on the GCMs and emission scenarios used (Harding et al. 2012). Furthermore, more recent work based on regional climate models (RCMs), rather than GCMs, suggests that the sensitivities of streamflow to climate change may be somewhat less in RCMs than GCMs because of the inability of GCMs to represent the high-elevation runoff source areas for the
Colorado River. These RCM scenarios also mostly suggest reductions in twenty-first-century Colorado River discharge (2040-69 relative to 1970-99), as do their related GCMs (Gao et al. 2011).

A sensitivity study by Das et al. (2011) suggests that among the major western U.S. river basins, reductions in discharge caused by warming would be largest in the Colorado River basin. This can be explained by the fact that the semiarid Colorado basin yields a relatively small increment of runoff relative to the precipitation it receives. Any increase in evapotranspiration, from warmer temperatures or shifts in seasonality, produces a larger percentage loss in the amount left for runoff in the Colorado basin compared to more humid river basins. Also unique to the Colorado basin is the size of its reservoirs relative to annual streamflow, with total storage relative to annual inflow ratios of over 4 (vs about 0.3 in the Columbia River basin, for example). Therefore, for the basin as a whole, water management implications of runoff change are controlled by annual rather than shorter period discharge volumes, which is fundamentally different than other major reservoir systems. Our analysis, therefore, focuses on annual, not seasonal, changes. This large ratio and current water demands also indicate that adding additional reservoirs will likely not improve basin water supply or water management (Burges 1991).

Collectively, the uncertainties among studies have stimulated an interesting scientific debate, but to many practitioners this appears to be a tangle of conflicting predictions. This poses a serious impediment to water managers, who are faced with securing an adequate water supply in the region. The obvious questions to scientists from the water management community are these: Why is there such a wide range
AFFILIATIONS: VANO AND LETTENMAIER-Department of Civil and Environmental Engineering, University of Washington, Seattle, Washington; UdALL-Western Water Assessment, University of Colorado Boulder, Boulder, Colorado; CAYAN—Division of Climate, Atmospheric Sciences, and Physical Oceanography, Scripps Institution of Oceanography, and U.S. Geological Survey, La Jolla, California; DAs* AND HIDALGO*-Division of Climate, Atmospheric Sciences, and Physical Oceanography, Scripps Institution of Oceanography, La Jolla, California; OVERPECK-Institute of the Environment, The University of Arizona, Tucson, Arizona; BREKKEU.S. Bureau of Reclamation, Denver, Colorado; HARTMANN-Arid Lands Information Center, The University of Arizona, Tucson, Arizona; HoerLING AND WeBB-NOAA Earth System Research Laboratory, Boulder, Colorado; MCCABE-U.S. Geological Survey, Denver, Colorado; MorINo-Laboratory of Tree-Ring Research, The University of Arizona, Tucson, Arizona; WERnER-National
Weather Service, Colorado Basin River Forecast Center, Salt Lake City, Utah

*CURRENT AFFILIATIONS: DAS-CH2M Hill, San Diego, California; HIDALGO-School of Physics, University of Costa Rica, San José, Costa Rica

CORRESPONDING AUTHOR: Dennis Lettenmaier, Department of Civil and Environmental Engineering, University of Washington, Box 352700, Seattle, WA 98195-2700

E-mail: dennisl@uw.edu

The abstract for this article can be found in this issue, following the table of contents.

DOI:10.1175/BAMS-D-12-00228.1

A supplement to this article is available online (10.1175/BAMS-D-12-00228.2)

In final form 31 May 2013

(C2014 American Meteorological Society 
of projections of impacts of future climate change on Colorado River streamflow, and how should this uncertainty be interpreted?

To understand and reconcile differences in future streamflow projections, we have explored uncertainties in the methodologies and models on which they were based at multiple levels in the climatehydrology-water resources continuum. We find that no single factor can explain the differences; rather, they arise from multiple factors involving differences in methodologies and models. These differences, the nature and implications of which we summarize

\begin{tabular}{|c|c|c|c|c|c|c|c|}
\hline & $\begin{array}{l}\text { No. of } \\
\text { GCMs }\end{array}$ & $\begin{array}{l}\text { No. of } \\
\text { RCMs }\end{array}$ & $\begin{array}{l}\text { Emission } \\
\text { scenarios }\end{array}$ & $\begin{array}{c}\text { Total } \\
\text { projections }^{\mathrm{a}}\end{array}$ & $\begin{array}{c}\text { Spatial } \\
\text { resolution }\end{array}$ & $\begin{array}{c}\text { Type } \\
\text { downscaling }\end{array}$ & $\begin{array}{l}\text { Land surface } \\
\text { representation }\end{array}$ \\
\hline Seager et al. (2007) & 19 & - & SRES AIB & 49 & $\begin{array}{l}\sim 2^{\circ} \text { lat-lon } \\
(\sim 200 \mathrm{~km})\end{array}$ & - & GCM P - E \\
\hline Seager et al. (2013) & $16^{\mathrm{b}}$ & - & $\begin{array}{l}\text { CMIP5 } \\
\text { RCP8.5 }\end{array}$ & 43 & $\begin{array}{l}\sim 2^{\circ} \text { lat-lon } \\
(\sim 200 \mathrm{~km})^{\mathrm{c}}\end{array}$ & - & GCM P - E and runoff \\
\hline Milly et al. (2005) & 12 & - & SRES AIB & 24 & $\begin{array}{l}\sim 2^{\circ} \text { lat-lon } \\
(\sim 200 \mathrm{~km})\end{array}$ & - & GCM runoff \\
\hline $\begin{array}{l}\text { Christensen et al. } \\
(2004)\end{array}$ & 1 & - & ACPI BAU & 3 & $\begin{array}{l}1 / 8^{\circ} \text { lat-lon } \\
(\sim 12 \mathrm{~km})\end{array}$ & BCSD & VIC hydrologic model \\
\hline $\begin{array}{l}\text { Christensen and } \\
\text { Lettenmaier (2007) }\end{array}$ & II & - & $\begin{array}{l}\text { SRES A2 } \\
\text { and } \mathrm{BI}\end{array}$ & 22 & $\begin{array}{l}1 / 8^{\circ} \text { lat-lon } \\
(\sim 12 \mathrm{~km})\end{array}$ & BCSD & VIC hydrologic model \\
\hline Cayan et al. (2010) & $2^{d}$ & - & $\begin{array}{l}\text { SRES A2 } \\
\text { and } \mathrm{BI}\end{array}$ & 4 & $\begin{array}{l}\text { I/ } 8^{\circ} \text { lat-lon } \\
(\sim 12 \mathrm{~km})\end{array}$ & $\begin{array}{l}\text { Constructed } \\
\text { analogs }\end{array}$ & VIC hydrologic model \\
\hline $\begin{array}{l}\text { USBR }(20 I \mathrm{I} a) \\
\left(\text { approach } 3^{\mathrm{e}}\right)\end{array}$ & 16 & - & $\begin{array}{c}\text { SRES } A 2, \\
A I B \text {, and } B I\end{array}$ & 112 & $\begin{array}{l}1 / 8^{\circ} \text { lat-lon } \\
(\sim 12 \mathrm{~km})\end{array}$ & BCSD & VIC hydrologic model \\
\hline Gao et al. (20II) & 3 & 3 & SRES A2 & 3 & $50-\mathrm{km}$ grids & Dynamical & RCM runoff \\
\hline $\begin{array}{l}\text { Rasmussen et al. } \\
(2011)\end{array}$ & 1 & 1 & SRES A2 & 1 & $\begin{array}{l}\text { 2-, 6-, 18-, and } \\
36-\mathrm{km} \text { grids }\end{array}$ & $\begin{array}{l}\text { Pseudo-global } \\
\text { warming } \\
\text { approach }\end{array}$ & RCM runoff \\
\hline Gao et al. (20I2) & 4 & 4 & $\begin{array}{l}\text { SRES A2 } \\
\text { and AIB }\end{array}$ & 4 & $\begin{array}{l}50-\text { and } \sim 35-\mathrm{km} \\
\text { grids }\end{array}$ & Dynamical & RCM P - E \\
\hline $\begin{array}{l}\text { Hoerling and } \\
\text { Eischeid (2007) }\end{array}$ & 18 & - & SRES AIB & 42 & $\begin{array}{l}\text { Climate divisions } \\
\qquad(\sim 150 \mathrm{~km})\end{array}$ & $\begin{array}{l}\text { Downscaling } \\
\text { regression }\end{array}$ & PDSI with regression \\
\hline Cook et al. (2004) & 一 & - & 一 & 1 & $2.5^{\circ}$ lat-lon & - & PDSI reconstruction \\
\hline $\begin{array}{l}\text { Woodhouse et al. } \\
(2006)\end{array}$ & - & - & - & I & $\begin{array}{l}62 \text { tree-ring } \\
\text { chronologies }\end{array}$ & - & Proxy reconstructions \\
\hline Meko et al. (2007) & - & - & - & I & $\begin{array}{l}\text { II chronologies, } \\
\text { upper basin }\end{array}$ & - & Proxy reconstructions \\
\hline $\begin{array}{l}\text { McCabe and } \\
\text { Wolock (2007) }\end{array}$ & $\begin{array}{c}\text { Estimate } \\
2^{\circ} \mathrm{C}^{f}\end{array}$ & - & - & 2 & $62 \mathrm{HUC} 8 \mathrm{~s}$ & - & $\begin{array}{l}\text { Percentage adjust- } \\
\text { ment based on TWB } \\
\text { model and proxy } \\
\text { reconstructions }\end{array}$ \\
\hline $\begin{array}{l}\text { USBR (20Ila) } \\
\text { (approach 8e) }\end{array}$ & - & - & - & $\begin{array}{l}1244 \text { and } \\
1000 \text { traces }^{g}\end{array}$ & $\begin{array}{l}\text { II chronologies, } \\
\text { upper basin }\end{array}$ & - & Proxy reconstructions \\
\hline
\end{tabular}

${ }^{\text {a }}$ Total projections include multiple runs for the same GCM and emission scenarios.

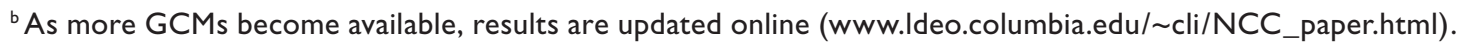

'Spatial resolution for GCMs in CMIP5 are, on average, smaller than those in earlier assessments (Seager et al. 20I3).

${ }^{d}$ A total of 12 GCMs were used, but only 2 were downscaled for more detailed analysis of droughts.

${ }^{\text {e }}$ As specified in Fig. I.

${ }^{f}$ Two warming scenarios: $0.86^{\circ}$ and $2^{\circ} \mathrm{C}$ increases; $0.86^{\circ} \mathrm{C}$ was based on measured trend in upper basin annual temperature during the twentieth century and $2^{\circ} \mathrm{C}$ warmer scenario was based on GCM scenarios.

${ }^{\mathrm{g}}$ Resampled using paleoresampled (I244) and paleoconditioned (1000) methods to generate 50-yr periods. 
below, highlight the need for the research community to better identify, effectively communicate, and focus research efforts to reduce climate uncertainties.

Future streamflow projections are also complicated by the Colorado River's large natural variability (Fig. 2). When the Colorado River Compact, which allocated water between the upper and lower basins, was signed in 1922, less than 30 years of streamflow data had been collected, and thus there was little understanding of the system's natural variability at interdecadal time scales. Since then, methods have been developed to extend the instrumental record based on paleoclimate studies (Fig. 2, bottom panels), which now date back to $268 \mathrm{BC}$ in some locations in the western United States (e.g., Cook et al. 2004; Woodhouse et al. 2006; Meko et al. 2007; Routson et al. 2011). Although these paleoreconstructions were not included in the future climate studies mentioned above, these long-term records contain droughts more severe than the historical record and have often been considered proxies for future flows (e.g., USBR 2007b, 2011a), which further increases the impression of conflicting research results. Reinforcing this impression, a recent study suggests that even the existing tree-ring-based flow reconstructions may underestimate the magnitude of interdecadal-scale to centennial-scale drought variability (Ault et al. 2013).

To address the questions posed above, we explore four possible causes for the wide range of future Colorado River projections and follow with a discussion of how paleoclimate records relate to future projections. We also discuss the connection of this information to planning and management and conclude by summarizing future research and presenting an interpretation for decision makers. Throughout the paper, we highlight seven "lessons" that help place individual studies within the broader research context. By providing this context, researchers can reduce uncertainty in the interpretation of results and thus provide information more useful to decision makers.

\section{SOURCES OF UNCERTAINTY IN FUTURE} PROJECTIONS. We identify four major sources of disparities in future projections (the four subsections in this section), ranked from greatest to least importance using information from this and other studies. Two sources of disparities arise from differences in the specific GCM projections used (including both differences in the GCMs and emissions scenarios) and differences in the statistical downscaling methodologies (ranked first and fourth, respectively). These two sources of disparities among studies can be partially addressed by standardizing methodologies. In contrast, the other two-spatial scale and topographic dependencies of climate change projections (ranked second) and differences in the sensitivities of land surface hydrology model representations to precipitation and temperature change (ranked third) - are somewhat more complex and require further analyses. Together these underscore the imperative of gaining a better understanding of uncertainties inherent in the predictions and the need to better communicate these uncertainties to the larger water management community.

GCM and emission scenario selection. Future climate can be represented in many ways, but most climate change assessments rely on GCM output for multiple greenhouse gas emission scenarios [e.g., IPCC Special Report on Emissions Scenarios (SRES) A2 from AR4 and representative concentration pathway (RCP) 8.5 from the Fifth Assessment Report (AR5); see Nakicenovic and Swart 2000; Moss et al. 2010]. GCM projections vary in their internal model dynamics and thus have wide ranges of precipitation change as well as in other surface atmospheric variables (e.g., surface air temperature, and downward shortwave and longwave radiation). These differences relate to how GCMs represent important physical processes-for example, stratospheric resolution (Scaife et al. 2012; Karpechko and Manzini 2012) and tropical Pacific sea surface temperature responses to anthropogenic forcing (Seager and Vecchi 2010) — as well as natural variability that can operate on time steps that are multidecadal or longer (Deser et al. 2012; Karnauskas et al. 2012). Recent studies have dealt with these differences by using projections from multiple GCMs to characterize future projections more fully. The selection of which GCMs are used [e.g., output from over 20 GCMs was archived by the Program for Climate Model Diagnosis and Intercomparison (PCMDI) that were run for the IPCC AR4] has been based on a range of criteria, but often instead of model performance, the GCMs used have hinged upon model output availability at the time the study was conducted. The choice of models and emission scenarios (Table 1), however, can have substantial implications. Some studies have used only one GCM and one emission scenario, and therefore they have a single projection of future runoff. This was the case in Christensen et al. (2004), who found declines of $18 \%$ in the mean annual discharge of the Colorado River by the midtwenty-first century with the Accelerated Climate Prediction Initiative's (ACPI) "business as usual" (BAU) global greenhouse gas emissions scenario for the Parallel Climate Model GCM. Later work (C\&L) 
using similar methods but applied to 11 GCMs with a roughly equivalent emission scenario (A2) found average declines of $6 \%$, with a range from a $40 \%$ decline to a $17 \%$ increase. The USBR (2011a) study also used essentially the same approach as in Christensen et al. (2004) but expanded simulations to include 16 GCMs. The A2 emission scenario's average for the USBR (2011a) study had declines of $10 \%$ at Lees Ferry, Arizona (slightly upstream of the location for which flows were reported by C\&L) (data from J. Prairie 2012, personal communication), which included multiple runs for certain GCMs for a total of 36 simulations that produced a range in mid-twenty-first-century annual runoff change from $-40 \%$ to $+21 \%$ [see Harding et al. (2012) for additional comparisons].

In addition to GCM selection, scenarios for future greenhouse gas concentrations must be specified. This affects the magnitude of temperature and precipitation changes-generally higher concentrations translate to larger temperature increases, especially in the latter part of the twenty-first century. In the IPCC AR4, these increasing concentrations (e.g., B1, B2, A1B, A2) were determined through emission scenarios as described by Nakicenovic and Swart (2000). In the AR5 simulations, emissions are represented somewhat differently-as representative concentration pathways (e.g., RCP4.5, RCP6.0, RCP8.5) (Moss et al. 2010).

Figure 3 demonstrates how both GCM and emission scenario selection can influence results by showing differences in precipitation minus evaporation $(P-E$; equivalent to runoff in the longterm mean, and $E$ includes evapotranspiration) for different GCMs across the same A1B emission scenario (Fig. 3a) and different emission scenarios across the same 11 GCMs (Fig. 3b). Data were downloaded from online (http://esg.IInl.gov: 8080 /home/publicHomePage.do) and latent heat for the Geophysical Fluid Dynamics Laboratory Climate Model, version 2.1 downloaded elsewhere (http:// kage.Ideo.columbia.edu:8I). We use a single run from every model, thus weighing all the GCMs' natural variabilities equally, and average values for eighteen $2^{\circ} \times 2^{\circ}$ grids that cover the basin, with GCM output regridded to fit a consistent grid. Figure 3a shows $P-E$ anomalies for the A1B scenario from 19 GCMs (top panel), whose output was analyzed by Seager et al. (2007), in comparison with the same $P-E$ anomalies over the same region for the 11 GCMs (middle panel) used by C\&L (almost two-thirds of the models used by Seager et al.2007). Anomalies of $P-E$ 
(a) Different GCMs, A1B scenario

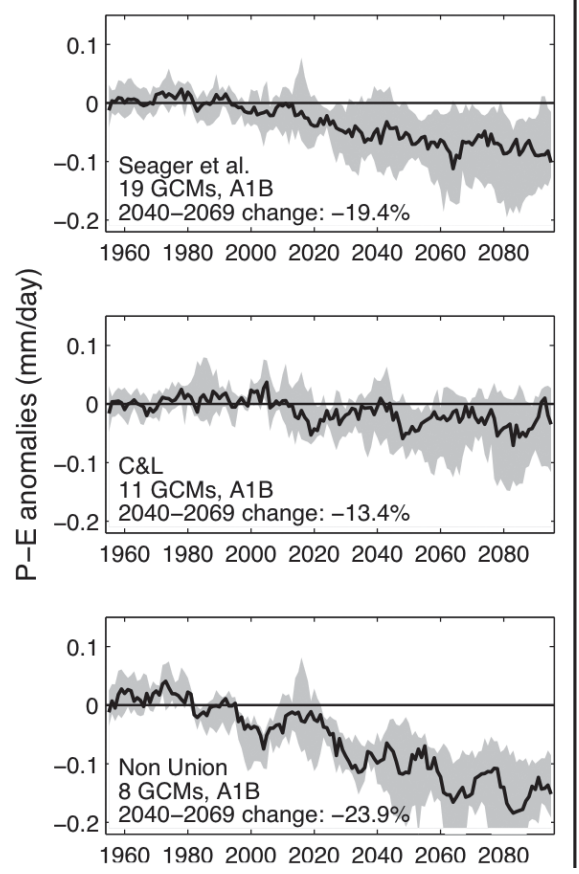

(b) Same GCMs, Different scenarios

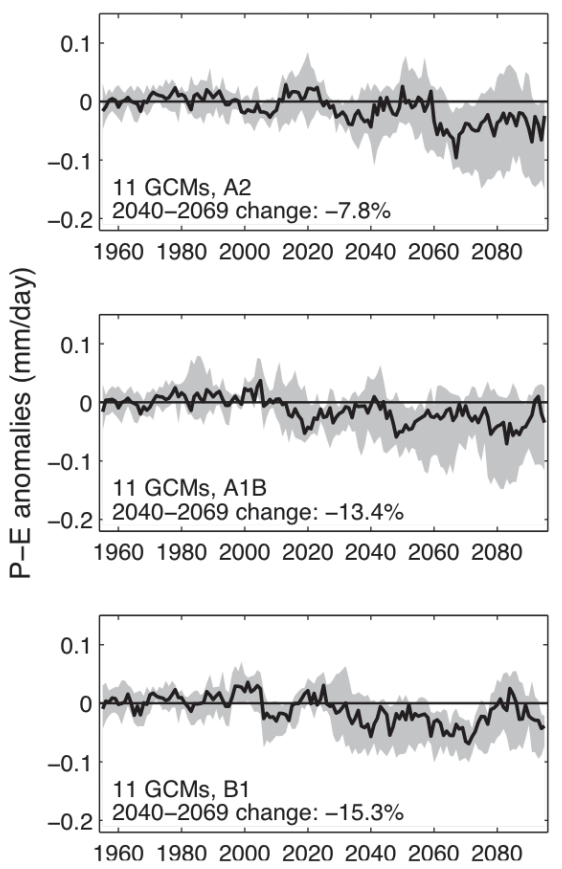

FIG. 3. Precipitation-minus-evaporation anomalies from GCM output for grids over the upper basin (which contribute to flows at Lees Ferry). Anomalies are relative to the individual GCM's climatology from 1950 to 2000. Anomalies have been filtered using a 10 -yr moving average. Black lines are median values; gray area is the interquartile range. (a) The effect of differences in GCMs for just the AIB scenario, where the nonunion GCMs are those included in Seager, but not in C\&L. (b) Differences between scenarios (A2, AIB, and BI) for just the II GCMs used in C\&L.

in GCMs included in Seager et al. but not in C\&L are lower ("Non Union" GCMs, bottom-left panel), indicating that Seager et al.'s study included drier GCMs than did C\&L. Changes in mid-twenty-first-century $P-E$, averaged across GCMs for 2040-69 relative to $1950-99$, also indicate that Seager et al.'s (2007) models had more negative $P-E$ values (-19.4\%) than C\&L (-13.4\%). Figure 3 differences are strictly from GCM output and are directly comparable, whereas streamflow comparisons between these two studies involve methodological differences (Seager et al. use GCM output similar to what we report here, whereas C\&L employed a higher-resolution hydrological model that essentially was used, after downscaling, as a postprocessor to GCM output). Nevertheless, comparisons of GCM $P-E$ suggest that model selection may be a major source of differences between the Seager et al. (2007) estimated runoff declines ( 19\%) and the much smaller projected changes reported by C\&L ( $6 \%$ decline for $\mathrm{A} 2, \sim 7 \%$ decline for $\mathrm{B} 1$ ).

The two studies also differ in the emissions scenarios they report. Seager et al. (2007) used A1B emissions scenarios, whereas C\&L used A2 and B1. Figure $3 \mathrm{~b}$

shows $P-E$ anomalies for the 11 GCMs in C\&L for all three scenarios. For A2, this results in mid-twenty-firstcentury declines of $7.8 \%$, which are similar to those reported by C\&L ( 6\%). Similar GCM and emission scenarios are, however, not a guarantee that studies using different methodologies for producing runoff estimates will agree, as demonstrated by B1 scenario changes; C\&L, who used a hydrology model to generate runoff, reported average runoff declines of approximately $7 \%$, whereas our $P-E$ calculation estimates declines of $15.3 \%$. This figure also illustrates how the time period of analysis matters, a 30-yr time slice in the mid-twenty-first century (where B1 declines of $15 \%$ are greater than $A 2$ of $8 \%$ ) does not capture the same trend between emission scenarios as in the late-twenty-first century (where the 2070-99 average B1 declines of $10 \%$ are less than A2 declines of 17\%). This change is due to both the strength of the humaninduced signal and random natural climate variability in GCMs, which can either hide or amplify radiatively forced trends, making a climate change signal difficult to detect [see Deser et al. (2012) and Harding et al. (2012) for further discussion]. Furthermore, some GCMs archived for IPCC contribute an ensemble of multiple simulations for the same emission scenario. Typically, differences between ensemble members are less than differences among different GCMs and emission scenarios; however, some GCMs have larger ranges [see Fig. 2 in Seager et al. (2007) and Fig. 8 in Harding et al. (2012) for examples], implying a need to balance intramodel and intermodel variability in multimodel ensemble estimates.

LESSON I: Differences between studies are attributable in part to differences in the GCMs used. Differences can arise from 1) how many and which GCMs were used and 2) the emission scenarios used and time period over which changes are analyzed. In the 
Colorado basin, most GCMs used in AR4 project declines in (annual) precipitation [with the headwaters being close to the nodal line of drying to the south and wetting to the north, which implies greater uncertainty and an increased likelihood that results in future studies (e.g., AR5) may differ] and increases in temperature, although the magnitude of change depends strongly on which GCMs and emission scenarios are used. Natural variability can mask climate signals; however, on the whole, higher future greenhouse gas emissions translate to a warmer, and in most cases, drier climate, with larger decreases in Colorado River streamflow.

Spatial scale and topographic dependence of climate change projections. Runoff production in the Colorado River varies greatly across the complex terrain and climate of the basin, and also changes markedly with season and year. About $85 \%$ of the basin's runoff is produced from about $15 \%$ of its area-mostly in the high-elevation headwaters region (C\&L). Furthermore, although the amounts of summer and winter precipitation on average are roughly equal basinwide, winter precipitation is much greater in the headwaters and more efficiently produces runoff than does summer precipitation. Differences in the ability of models to represent the disproportionate contribution to Colorado River discharge of the relatively small high-elevation source areas can have important effects on a model's sensitivities to climate change. Offline hydrology model simulations, which are often employed to increase spatial resolution to better capture the hydrologic dynamics of the headwaters region (which reflect highly variable topographic, soil, and vegetation characteristics), use techniques such as Penman-Monteith, Thornthwaite, and related methods to estimate potential evapotranspiration and are, by construct, not coupled with (and hence, constrained by) the climate system. On the other hand, moisture recycling within the Colorado basin (one indicator of the constraining role the system might play) has been estimated to be quite small-less than $3 \%$ by Trenberth (1998).

1) Simulations of Land processes. We used a simple water balance model (McCabe and Markstrom 2007) to demonstrate how sensitive runoff is to the spatial resolution of climate forcing data (Fig. 4) - and hence, the ability of models to resolve high-elevation runoff source areas within the Colorado basin. This model, referred to as the Thornwaite water balance model (TWB), was previously used by McCabe and Wolock (2007) to investigate how future warming might impact the Colorado basin water supply. They ran the model for each of the 62 U.S. Geological Survey hydrologic unit code 8 (HUC8) subbasins above Lees Ferry, with monthly precipitation and temperature aggregated for each HUC8 from Parameter-Elevation Regressions on Independent Slopes Model (PRISM) data (www.prism.oregonstate.edu). The model was calibrated by tuning basinwide parameters that govern snow accumulation, snowmelt, and runoff. We used the model version and parameters from McCabe and Wolock (2011) and the same gridded climate forcing dataset used in Vano et al. (2012), with climate forcings aggregated at four spatial resolutions $\left(1 / 8^{\circ}\right.$, $1 / 2^{\circ}, 1^{\circ}$, and $2^{\circ}$ latitude-longitude). We calculated runoff averaged over the period 1975-2005 and calculated temperature sensitivities at each resolution using a $0.1^{\circ} \mathrm{C}$ increment change as in Vano et al. (2012).

In our simulations, as the model resolution was increased from $2^{\circ}$ to $1 / 8^{\circ}$, the simulated runoff from the upper basin increased from an average of 73 to $107 \mathrm{~mm} \mathrm{yr}^{-1}$, an increase of 45\% (Fig. 4, black line).
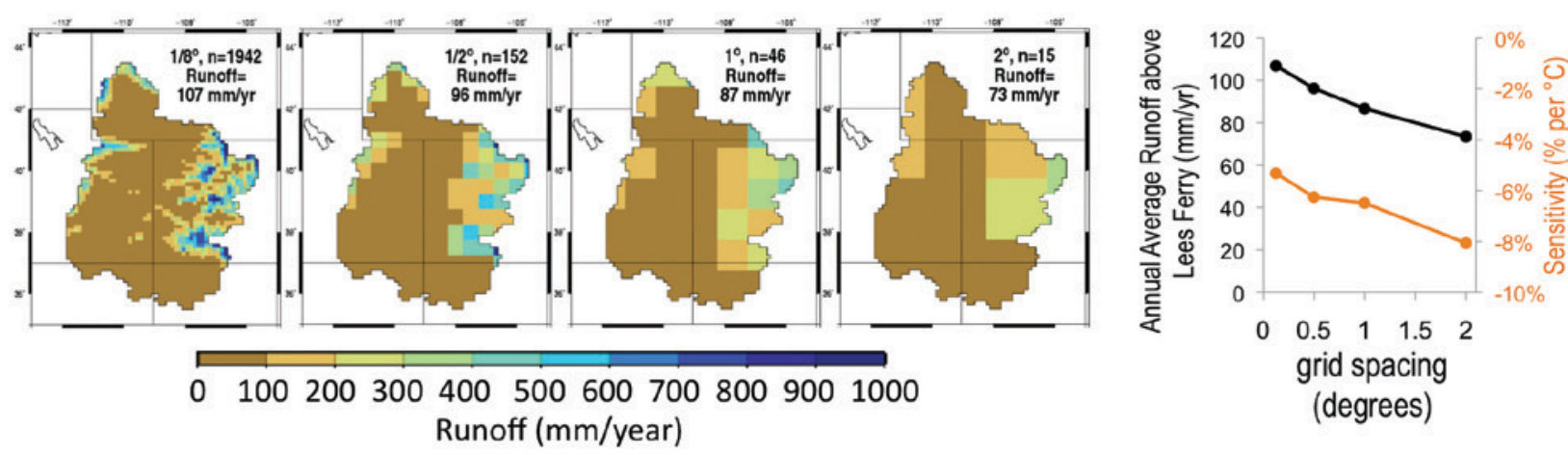

FIG. 4. Influence of spatial resolution on upper Colorado River basin runoff. When the $1 / 8^{\circ}$ climate forcing dataset (monthly temperature and precipitation) was aggregated to $1 / 2^{\circ}, 1^{\circ}$, and $2^{\circ}$ resolutions, the annual average TWB modeled runoff (black line in far right panel) declines and temperature sensitivities (orange line in far right panel) become more negative. 
Similarly, as the model resolution increased, the basin's sensitivity to temperature increases became less negative-in other words, higher-resolution simulations were less sensitive to temperature change (Fig. 4, orange line). We believe that the mechanisms that underlie the sensitivity's dependence on spatial resolution are twofold (keeping in mind that these are offline simulations; that is, the land surface is forced by, but does not feed back to, the atmosphere): 1) higher-resolution simulations are colder in the headwaters, where a majority of the basin's runoff is generated; these colder temperatures accumulate larger snowpacks that more efficiently generate runoff because their larger spring pulses are more likely to be associated with soil saturation, and 2) in coarser-resolution simulations the highest elevations are lower, hence temperatures are warmer, which results in higher rates of evaporation and more rain than snow, which increases water availability and subsequently evaporation. The results shown in Fig. 4 are qualitatively similar to those reported in Hoerling et al. (2009) in their reevaluation of Hoerling and Eischeid's (2007) results, where they used a highspatial-resolution model, and found considerably smaller projected future climate runoff declines than in their earlier (coarse resolution) study.

More detailed process-based hydrology modelsfor example, the Variable Infiltration Capacity (VIC) model-account for the effects of finer-spatial-scale topographic variations through the use of elevation bands (i.e., meteorological forcings are adjusted according to a lapse rate and snow processes are simulated at multiple elevations within a single grid). Haddeland et al. (2002) found that in the Columbia River basin, which also has snowmelt-dominated hydrology, when elevation bands were not used, VIC runoff simulated at a coarse $2^{\circ}$ spatial resolution was $15 \%$ lower than simulations at much higher $\left(1 / 8^{\circ}\right)$ resolution; however, when elevation bands (at 200-m-elevation intervals) were represented, the difference was reduced to $4 \%$. In other words, whether through finer grid resolution $\left(2^{\circ}\right.$ vs $\left.1 / 8^{\circ}\right)$ or by use of elevation bands, a hydrologic model's representation of the effects of orography can strongly affect hydrologic predictions at the basin scale in topographically complex river basins.

i) Simulations of ATMOSPHeRIC PROCEsSes. Atmospheric models are also affected by complex terrain that can affect how temperature changes translate to changes in runoff. In the Colorado River headwaters in particular, estimates of future flow will benefit from using high-resolution atmosphere models to simulate high-elevation snow (as suggested by
Seager and Vecchi 2010). RCMs simulate processes similar to GCMs but at a much finer resolution. For this reason, computational requirements have often constrained the time period and spatial domain for RCM simulations-although this restriction has been relaxed somewhat in recent studies, like the North American Regional Climate Change Assessment Program (NARCCAP; Mearns et al. 2012). Many studies with RCMs have highlighted the importance of representing the effects of complex terrain in climate simulations, particularly the implications of snow processes (e.g., Rauscher et al. 2008; Rasmussen et al. 2011; Gao et al. 2011, 2012; Dominguez et al. 2012; Wi et al. 2012). For example, Rasmussen et al. (2011) found a spatial resolution coarser than $6 \mathrm{~km}$ results in overestimating low-elevation and underestimating high-elevation snowfall in the Colorado River headwaters by $20 \%-40 \%$. How an improved regional simulation of snow processes in topographically complex regions translates into more realistic regional climate change sensitivity has yet to be determined. Although this might be done in a regional climate modeling context, a consensus on RCM sensitivities to climate change in the Colorado River basin does not yet exist (e.g., Rauscher et al. 2008; Gao et al. 2011; Rasmussen et al. 2011; Gao et al. 2012). Furthermore, complications with the specification of boundary conditions suggest that it might be better attempted through use of global simulations over a range of spatial resolutions spanning the approximate range in our Fig. 4. Racherla et al. (2012, p. D20118) note, for instance, in a more general analysis of the added value of RCM downscaling "that there is not a strong relationship between skill in capturing climatological means and skill in capturing climate change," and we believe that this is a central unresolved issue in the context of understanding the climatic sensitivity of snow-dominated mountainous regions.

LESSON 2: Spatial resolution of both land surface and atmospheric models is critical to the realistic representation of the changes in future hydrology of the Colorado basin - both mean conditions and variability. The basin's headwater areas accumulate much of the precipitation that is available for runoff, an effect amplified by reduced evaporation resulting from colder temperatures and snowpack at these elevations. As a result, the water fluxes from models with coarser spatial resolution tend to be more sensitive to change from both warming and precipitation reductions, the details of which warrant further investigation. Runoff changes (not magnitudes) calculated directly from GCM output ( 200-km spatial resolution at present) 
or from other methods based on basinwide areaaverage temperature and precipitation change likely overestimate runoff change sensitivities, and should be interpreted with considerable caution.

Land surface representations. In the Colorado River basin, there is a substantial range in the sensitivity of different land surface hydrology models to changes in climatic variables-that is, the fractional change in runoff associated with a given precipitation or temperature change. Vano et al. (2012), for instance, compared the land surface response of five LSMs (with two versions of Noah) to changes in precipitation and temperature (Fig. 5). Changes in precipitation are magnified in runoff changes, with lower flows being more sensitive to precipitation changes. This sensitivity can be expressed as an elasticity, defined as percent change in annual model runoff divided by percent change in annual precipitation. Vano et al. (2012) found elasticities ranging from a little over 2 to 6 at Lees Ferry depending on the model and reference condition (the derived value from observations is about 2), and the elasticities among models were reduced to between about 2 and 3 when model biases (mostly underestimates of runoff) were accounted for. Similarly, the sensitivity of modeled runoff to temperature, defined as percent change in annual runoff for an imposed increase in annual temperature, differed among LSMs from about $-3 \%$ to $-10 \%{ }^{\circ} \mathrm{C}^{-1}$ increase in annual basin-average temperature, with no evident change in the range of sensitivities with model biases.

The temperature sensitivity depends on the model's physical parameterizations. When temperature changes were applied only to the maximum temperature instead of holding the temperature range constant-an experiment that effectively generated larger changes in net radiation and vapor pressure deficit-temperature sensitivities roughly doubled for most models. Although there were substantial spatial variations in temperature sensitivities (and precipitation elasticities), differences among models were generally smaller in the headwater regions that produce most of the runoff. The form of precipitation (rain or snow) was dependent on temperature, but this was consistent across models.

In addition to elasticities and temperature sensitivities reported in Vano et al. (2012), we computed the same metrics for two other hydrological models at Lees Ferry (also in Fig. 5). The National Weather Service Colorado Basin River Forecast Center's operational version of the Sacramento Soil Moisture Accounting (SAC) model (Burnash et al. 1973) is essentially a spatially lumped (for 29 Colorado River subbasins) version of the SAC-distributed version reported by Vano et al. (2012). The operational version had an elasticity of 2.4 (vs 2.6 for the distributed version) and temperature sensitivity of $-4 \%$ (vs $-5 \%$ ) per ${ }^{\circ} \mathrm{C}^{-1}$ of annual warming. This is an updated version of the model used by Nash and Gleick (1991). We also calculated sensitivities using the simple TWB computation described in the previous section. This is a slightly updated version of the model used by McCabe and Wolock (2007) in their study of climate change in the Colorado basin, with key differences being that we applied the model using the same $1 / 8^{\circ}$ grid mesh,
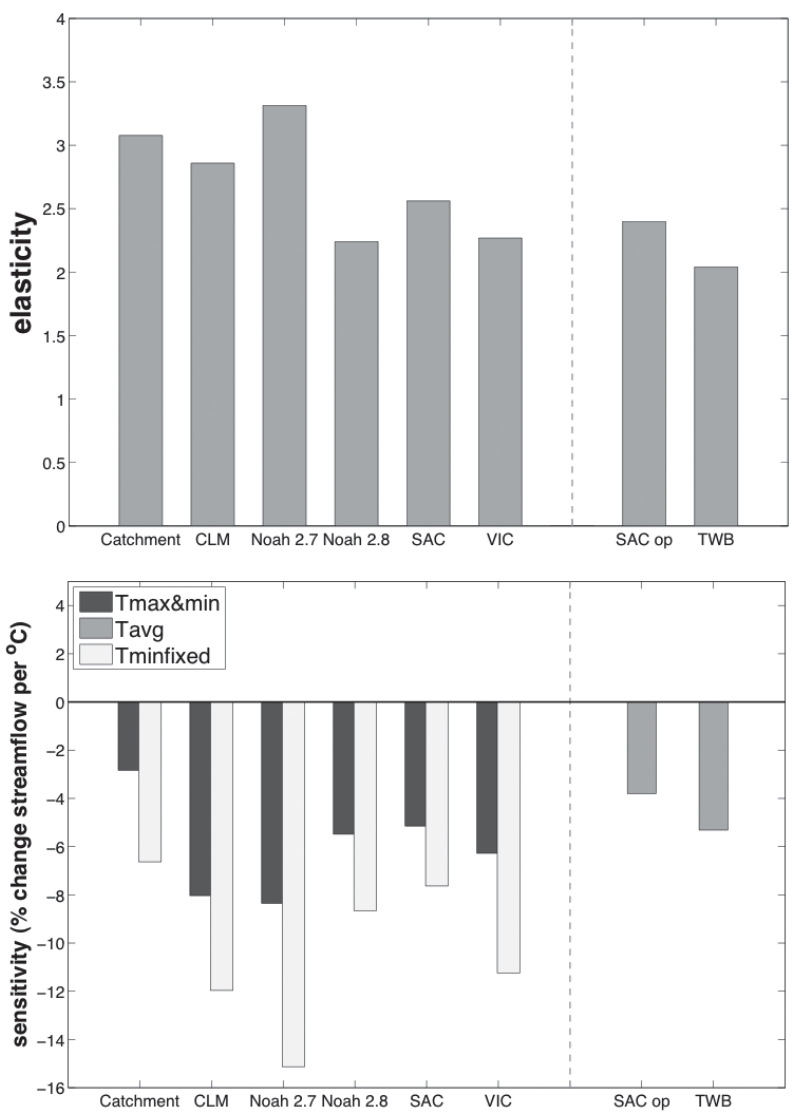

FIG. 5. (top) Precipitation elasticities and (bottom) temperature sensitivities at Lees Ferry. Values to the left of the dashed line are from Vano et al. (2012); values to the right of the dashed line are the Sacramento Operational (SAC op) model and the TWB computations. Tmax\&min shows sensitivity values that result from changes to both minimum and maximum temperatures, whereas Tminfixed shows results from changes applied only to maximum temperatures [see Vano et al. (2012) for details]. SAC op and TWB models only use a single average temperature (Tavg). Note: some models are better able to reproduce observed hydrologic characteristics, providing some basis for identifying preferred models; see Vano et al. (2012) for details. 
climate dataset, and $+0.1^{\circ} \mathrm{C}$ temperature perturbation used by Vano et al. (2012). McCabe and Wolock (2007) found a basinwide $0.86^{\circ} \mathrm{C}$ temperature increase resulted in an $8 \%$ streamflow reduction (equivalent to $\left.-9 \%{ }^{\circ} \mathrm{C}^{-1}\right)$, whereas we found a decline of $5 \%{ }^{\circ} \mathrm{C}^{-1} \mathrm{using}$ $\mathrm{a}+0.1^{\circ} \mathrm{C}$ temperature change. They did not report precipitation elasticity; our result was 2.0. Generally, values reported in Fig. 5 are also similar to values in Fig. 3 of Tang and Lettenmaier (2012) for Colorado basinwide values of elasticity (between 1.8 and 2.2), whereas their temperature sensitivities (between -2\% and $-4 \%{ }^{\circ} \mathrm{C}^{-1}$ derived using regression equations from GCM output) are somewhat smaller in absolute value.

To test for robustness, we also calculated hydrologic sensitivities using different historical climate datasets and time periods. Specifically, we calculated precipitation elasticities and temperature sensitivities using the historical gridded datasets of Maurer et al. (2002), Hamlet and Lettenmaier (2005), Wood and Lettenmaier (2006), and the PRISM Climate Group as described in Daly et al. (1994), averaged across different time periods with varying lengths (e.g., 1975-2005, 1990-99, 1895-2006). In general, runoff change differences are considerably less sensitive to differences in historical datasets than they are to differences in hydrology models (and how net radiation and vapor pressure forcings were derived).

LESSON 3: Land surface hydrology models exhibit substantial differences in their sensitivities of runoff to temperature increases (approximately $-6.5 \pm$ $3.5 \%{ }^{\circ} \mathrm{C}^{-1}$ at Lees Ferry). Responses to precipitation change, when runoff biases are accounted for, are more consistent across models (between 2 and 3 at Lees Ferry). Differences in precipitation elasticity and temperature sensitivities among models are generally smaller in the headwater regions than elsewhere in the basin, although further research is needed to better understand these differences and how they relate to observations. In general, differences in precipitation elasticity and temperature sensitivity are independent of the datasets and historical periods for which evaluations are conducted.

Statistical downscaling methods. To represent hydrologic processes, such as snow accumulation and ablation, spatially distributed hydrologic models need inputs of order 10-20-km spatial and subdaily temporal resolution. In contrast, current-generation GCMs have spatial resolutions of about $200 \mathrm{~km}$. Furthermore, while the computational time step of most GCMs is $1 \mathrm{~h}$ or less, GCMs generally do not produce physically realistic precipitation (e.g., daily drizzle, storm interarrival times), which is the primary driver of the land surface hydrologic system, at time steps much less than 1 month. Through IPCC AR4, most GCM output was archived as monthly values; hence, temporal disaggregation to daily values is also required. The procedures that produce hydrologic forcings at appropriate spatial and temporal resolutions are usually referred to as statistical downscaling. They are essential for hydrological modeling even if dynamical downscaling (e.g., based on RCMs rather than GCMs) is used (Wood et al. 2004).

Statistical downscaling methods carry with them sources of uncertainty. We contrast here the bias correction and spatial disaggregation (BCSD) method, used in several studies noted above (including Christensen et al. 2004; C\&L; USBR 2011a), and the "delta method," described in Hamlet et al. (2010). We recognize that there are an increasing number of statistical downscaling methods (see "Future research directions" section) where each method has strengths and weaknesses that make it more or less appropriate for particular studies. Hamlet et al. (2010) discuss strengths and weaknesses of the BCSD and delta methods.

The BCSD method as described by Wood et al. (2004) is the most common approach in previous studies of the Colorado basin. The method maps the probability distribution of modeled historical precipitation and temperature to the probability distribution of observations; that is, if the modeled current climate precipitation in a given month and year is the $x$ th percentile of the climate model's (historical) distribution, then this is adjusted to the $x$ th percentile of the historical precipitation distribution for that month. This approach can be subdivided into bias-correction techniques and spatial disaggregation methods [as in USBR (2011b)], but for our purposes we consider this as a single downscaling method. In contrast, the delta method applies changes in mean monthly precipitation and temperature between current and future climate simulations, and applies those differences (typically as means ratios for precipitation and means differences for temperature) to a record of historical observations.

We contrast the BCSD approach as used in C\&L with the delta method based on 30-yr average monthly changes in temperature and percentage changes in precipitation for 2040-69 compared with 1950-99 across the basin, applied to gridded historical (monthly) observations for 1950-99 generated by Maurer et al. (2002). These monthly delta changes are then applied to every day in the historical record to create a future simulation (a 50-yr time series of 2040-69 climate change). Figure 6 compares the percentage difference 
in flows at Lees Ferry for individual GCM simulations using these two methods to generate input for the VIC hydrologic model, as used in C\&L. The delta method tends to generate larger declines in future flows (by a factor of almost 2 on an annual average basis) than the BCSD method. The 11-model average decline is $7 \%$ at Lees Ferry with the BCSD method compared to $13 \%$ for the delta method for the A2 scenario. For B1 scenario results (not shown), BCSD had average declines of $8 \%$, while the delta method had declines of $11 \%$. The differences between downscaling methods (which is at most 15\% for either scenario; orange bars in Fig. 6), however, are considerably less than the differences of mid-twenty-first-century downscaled GCM responses relative to historical streamflows, which have a BCSD range of $-42 \%$ to $+18 \%$ (with an interquartile range of $-17 \%$ to $+4 \%$ ) for $\mathrm{A} 2$ and $-26 \%$ to $+16 \%$ (interquartile range from $-16 \%$ to $0 \%$ ) for B1. The important aspect of an appropriate downscaling approach is that it reproduces space-time attributes of GCM changes. In this example, in the Colorado basin the spatial distribution and broad temporal characteristics (year-to-year seasonality) matter. The BCSD method and related approaches (see "Future research direction" section) capture this in a more sophisticated way than the delta method and therefore are arguably more desirable.

LESSON 4: The choice of downscaling method can affect the magnitude of the derived climate signal, leading to differences in measures such as long-term projected runoff changes that for some individual ensemble members can be comparable to differences among individual GCMs, although, on average, these differences are smaller. Differences in downscaling methods also translate to important differences in seasonal changes and extreme events. Downscaling methods should therefore be carefully evaluated and selected. Unlike GCM selection, where multiple models delineate the range of future projections, the most appropriate downscaling technique depends on what questions a study intends to address.

\section{PAST RECORDS PROVIDE CONTEXT FOR FUTURE PROJECTIONS. When plan-} ning for the future, process-based models reflect our best scientific understanding of future impacts. It is, however, also helpful to look to the past, particularly given emerging evidence that GCMs may underestimate the risk of decadal and multidecadal drought (Ault et al. 2012). Records of past flows and droughts, including paleoclimatic records, are being used increasingly in the Colorado River basin to help managers plan for similar events in the future (e.g., Woodhouse and Lukas 2006; USBR 2007b). Droughts in the 1930s and 1950s are commonly used in planning, but provide only a limited perspective of what could occur in the future. Paleoclimate reconstruction methods extend the record backward in time well prior to the beginning of the instrumental record. These studies provide more understanding of the range of drought variability, for instance, than is possible solely through examination of the instrumental record (e.g., Woodhouse and Lukas 2006). Stockton and Jacoby (1976, p. vii) were the first to reconstruct streamflows at Lees Ferry with a tree-ring analysis that extended back to 1512 . The reconstructed annual hydrographs caused concern-as their abstract cautioned, "when the results of our analysis are viewed in the context of future demand for water usage in the Upper Colorado River basin, it is apparent that projected demand could soon outstrip the natural annual supply of surface water." This study has been followed by many others, which refined reconstruction methods and extended

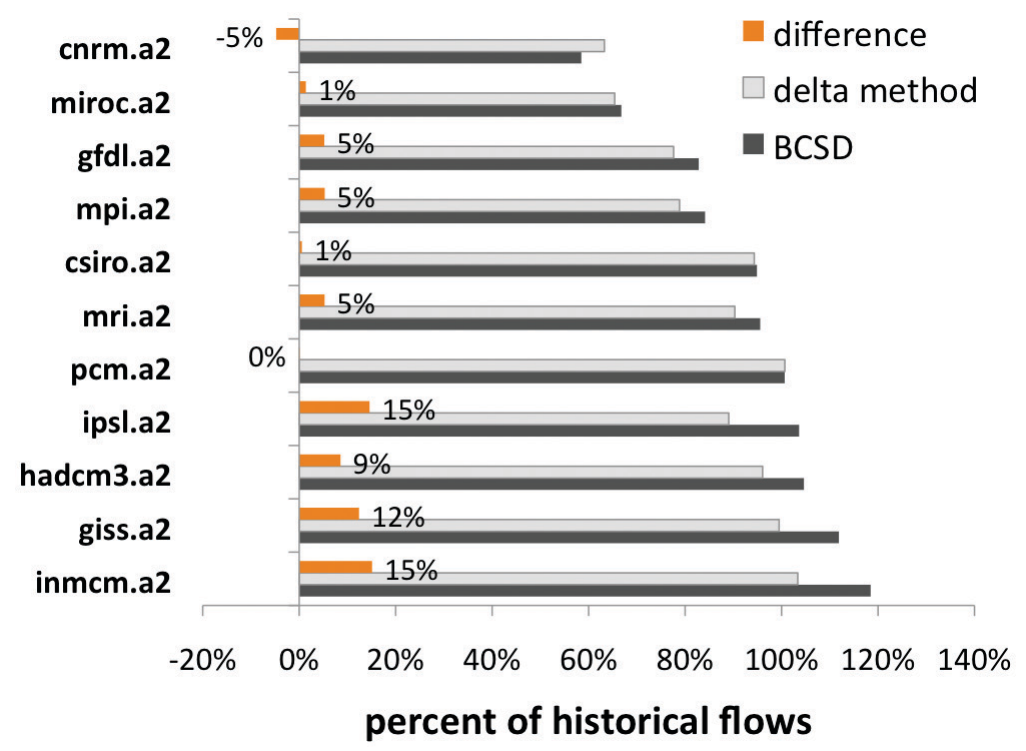

FIG. 6. Comparison of BCSD downscaling from C\&L with a deltamethod downscaling approach for Lees Ferry in the 2040-69 future period for A2 emission scenarios. On average, the BCSD approach has a decline in streamflow of $7 \%$ (average values of $93 \%$ ), whereas with the delta method, declines are $13 \%$ (average values of $87 \%$ ). Differences are the BCSD approach minus the delta-method approach. 
the record further (Hidalgo et al. 2000; Woodhouse et al. 2006; and others). Meko et al. (2007) produced a 1200-yr dataset for the entire upper Colorado River basin, and recently, Routson et al. (2011) generated a 2200-yr tree-ring reconstruction for the nearby Rio Grande headwaters region in Colorado. Although methods and datasets used in reconstruction studies differ, they all indicate that the period used in the 1922 Colorado Compact to determine water allocations was exceptionally wet (Woodhouse et al. 2006) and that the basin has a history of multidecadal dry periods, referred to as "megadroughts" (Fig. 2).

Paleoclimate records are key to assessing future projections by providing a longer record for context, helping to understand underlying climate mechanisms, and by providing a framework for evaluating how well models simulate the full range of past observed change. For example, the leading hypotheses for megadroughts has been shifts in tropical sea surface temperatures (Graham et al. 2007, 2011; Seager et al. 2007, 2008; Conroy et al. 2009; Oglesby et al. 2012) caused by either natural variability or a response to solar irradiance and volcanism variations (Emile-Geay et al. 2008). Independent of climate change considerations, paleodata prove it is realistic to expect conditions outside the range of recorded streamflow measurements-simply stated, there is reason to believe megadroughts will occur again (Woodhouse et al. 2010), although new work suggests that existing tree-ring reconstructions (including past streamflow) likely underestimate the full magnitude of interdecadal-scale to centennial-scale drought variability (Ault et al. 2013). Information on the length, duration, and extent of drought can also help identify global weather patterns that result in longer dry periods (e.g., variations in sea surface temperatures) (Hidalgo 2004; Woodhouse and Overpeck 1998). Advances in techniques, multiple indicators, and more paleoclimate data have improved the ability to understand the nature of seasonal changes in hydrologic conditions and land surface conditions such as snowpack (Pederson et al. 2011).

As with future GCM-based projections, paleoreconstructions using tree rings also have uncertainties and limitations. For instance, relationships between radial growth and streamflow generally do not account for some climate factors such as temperature through growing season length and snowpack storage of available moisture (Meko et al. 2007). Variations in reconstruction methods are reflected in reconstructed streamflows, especially in extreme years (Woodhouse and Brown 2001). Future and current drivers of hydroclimatic variability may also be novel with respect to the paleorecord (Woodhouse et al. 2010) - examples include anthropogenic influences on climate as well as land cover changes such as irrigated agriculture, grazing, dust on snow, urbanization, changing fire regimes through fire suppression, bark beetle infestations, and human ignition. Past droughts are also unlikely to be identical to current and future droughts (Woodhouse et al. 2010). There is evidence of this already, in that past megadroughts seem to be driven primarily by precipitation anomalies, whereas in the current drought, temperature appears to be playing a more important role (Cook et al. 2010; Woodhouse et al. 2010). This underscores the need for further attention to the role of temperature, such as in investigations by Cook et al. (2011) of the early twentieth-century pluvial.

Interpretation of megadroughts in a future context is somewhat complicated by the fact that the relative role of anomalously low precipitation (detected in most paleodroughts) is in contrast with the role of increasing temperature (a key element in the ongoing Colorado River drought, and implicated in future projections). Nonetheless, the superposition of megadroughts, as seen in paleoprojections, and a steady reduction in flows due to climate change should be considered in future planning.

LeSSON 5: To understand future streamflow and subsequent uncertainties, a comprehensive approach should be taken, including analyses of paleoclimate reconstructions as well as future projections. Together these two lines of discovery can be used to explore the basin's response to megadrought-like reductions in precipitation compounded by anthropogenic climate change, the real "worst case" scenario.

\section{PLANNING AND MANAGEMENT IMPLI-}

CATIONS. Planning in the face of uncertainty, across multiple spatial and temporal scales, is not a new problem for water managers. However, most water resource planning protocols are based on a fundamental assumption of stationarity, which implies that time-invariant statistical characteristics adequately represent expectations for the future (Salas 1993). Climate change and new paleoclimatological records belie the appropriateness of this stationarity assumption (Hartmann 2005; Milly et al. 2008), and while model-based studies offer the best prospect for uncovering likely future conditions not contained in the historical record, they do not provide definitive answers for decision makers.

Climate change science advances by using different approaches that are often not easily reconciled, 
while planners prefer clear, explicit characterizations of uncertainties that can be directly incorporated into risk-based calculations (Kerr 2011). Reconciliation of this dichotomy is a challenge that requires effort from both the science and management communities (see supplementary text at http://dx.doi.org//0.II75 /BAMS-D-12-00228.2 for specific examples from our work). It calls for more "actionable science" that is "sufficiently predictive, accepted, and understandable to support decision making, including capital investment decision-making" (Behar 2009, p. 4). It also implies exploring adaptation strategies that can proceed from a focus on the certainties presented by multiple studies, rather than uncertainties (in our effort we provide such messages for decision makers in the "Interpretations for decision makers" section). Capital investment decisions, particularly for projects that cannot be implemented incrementally and that have irreversible or multidecadal consequences, present a more intractable challenge for actionable science. These decisions need to require approaches that accommodate high uncertainty, complex systems, and ambiguity of model evidence, such as strategic scenario planning (Mahmoud et al. 2009) and the need for discussion about trade-offs between stranded costs, the costs of inaction, and the timeframe under which investments are evaluated for meeting criteria-for example, effectiveness and economic feasibility. Additionally, decision makers may not lack options, but rather need support from their constituencies for implementation of options that differ from past practice, in which case well-communicated science can be useful in building support.

It is also important to recognize that implications of climate uncertainties are not fully assessed by understanding hydrologic impacts. Considerations of different management strategies or planning options require hydrology model outputs be run through water management models that include physical processes (e.g., streamflow, solute transport), infrastructure (e.g., reservoirs, diversions), and policies (e.g., minimum instream flow requirements). Although uncertainties may be too great to satisfy design studies, management models (e.g., Colorado River Simulation System; USBR 2007a) can identify unanticipated sensitivities and thresholds in these complex systems, and can be used to evaluate trade-offs among options. Recent work by Brown and Wilby (2012) has proposed a "bottom-up" approach that, rather than being based solely on GCM information, uses distributional mapping to perturb historical probability distributions of streamflow. This may be a practical approach to identifying system vulnerabilities to climate risk that complements the information gained from a scenario-led strategy.

LESSON 6: The water/climate research and water management communities need to work more closely to generate the actionable science needed for planning and other decision making. Collaboration is particularly important under nonstationary conditions in order to develop and update information that allows management tools to represent the various sources of uncertainty. It is crucial that the management community seek decision approaches that accommodate uncertainty, complex systems, and ambiguity of model evidence, such as strategic scenario planning.

FUTURE RESEARCH DIRECTIONS. Figure 1 conceptualizes how the climate change studies mentioned above relate to each other and where future research might progress within the land-atmosphere continuum. For each study it is important to consider the following: 1) what emission scenarios, 2) what spatial scale and time period, 3) how many and which models (GCMs, RCMs, and hydrology), and 4) which methods of statistical downscaling and regression equations were used (Table 1). Ongoing and future research will offer additional insights into these various elements and help improve understanding of how future streamflow projections can be used by water managers. We present seven key areas where research is evolving, which are intended to provide an overview of ongoing work, not a ranking of research priorities.

i) New climate change projections: PCMDI is now making available climate change simulations produced for the IPCC AR5. The archive includes daily and monthly model output for most models (in contrast to AR4, for which the norm was monthly output) with longer multicentury control simulations, which are forced by known and estimated changes such as irradiance and volcanism, that can be used to compare GCMs to paleoclimate data. These new simulations will provide a basis for improving upon the AR4 simulations used in most studies cited above. For example, Seager et al. (2013) evaluate precipitation, evaporation, runoff, and soil moisture from GCM output used in AR5. These AR5-based scenarios should provide better estimates of how human emissions of greenhouse gases (e.g., via burning of fossil fuel) translate to changes in Colorado River discharge and should improve on the state of climate science represented in earlier scenarios. Furthermore, they should better represent stratosphere-troposphere 
coupling processes of relevance to the midlatitude storm track as well as tropical Pacific sea surface temperature variability and change, and they have improved spatial resolution relative to AR4. Nonetheless, there will remain inherent uncertainty in GCMs as in earlier assessments (e.g., Seager and Vecchi 2010; Ault et al. 2012) and natural variability will continue to complicate identification of trends (Deser et al. 2012; Knutti and Sedláček 2012). Thus, ensemble approaches will continue to be needed to delineate the range of future projections (e.g., Mote et al. 2011).

ii) Increased spatial resolution of climate models: Many GCMs have increased spatial resolution for the new CMIP5 simulations (Seager et al. 2013). Additionally, RCMs with higher spatial and temporal resolution have been run over the Colorado River basin (e.g., Rasmussen et al. 2011), and they generally provide more realistic representations of climate features (such as storm tracks and jet stream patterns) that are strongly topographically dependent. These higher-resolution simulations have important implications for the associated hydrologic impacts of climate change. Examples include the NARCCAP archive (Mearns et al. 2012) as well as recent work by Dominguez et al. (2012) and Wi et al. (2012).

iii) New statistical downscaling techniques: BCSD has been the standard approach in many of the key studies we have reviewed. There are, however, alternative approaches such as constructed analogs (Hidalgo et al. 2008; Maurer et al. 2010), multivariate adapted constructed analogs (MACA; Abatzoglou and Brown 2012), and hybrid delta (Hamlet et al. 2010) that are becoming more widely used and may constitute an additional source of uncertainty in future studies. PCMDI's archive of daily GCM output will make alternative downscaling methods more viable, but it will also require more evaluation of the appropriate applications of alternative approaches and how they relate to each other.

iv) Improved land surface simulations: LSMs continue to evolve and better represent land surface processes (e.g., Niu et al. 2011; Livneh et al. 2011). For example, the unified land model (ULM) combines the atmospheric exchange process of the Noah LSM with the surface water budget components of the SAC hydrology model (Livneh et al. 2011). Additionally, the coupling of atmospheric models with dynamic vegetation models will help better understand potential land cover feedbacks (Diffenbaugh 2005). v) New paleoclimate reconstructions and model evaluation: New records and new techniques continue to reveal better understandings of the climate of the past 2000 years, which can feed into more rigorous model evaluation efforts (e.g., Ault et al. 2012) and be used to understand how well state-of-the-art GCMs capture the realistic risk of multidecadal megadrought. For example, it is essential to test the new results of Ault et al. (2013), which indicate that current models (e.g., CMIP5) do not capture the full range of possible interdecadal to intercentennial drought risk.

vi) Improved observational records: Observations are crucial to improving our understanding of how future streamflow will respond to a changing climate. Of particular importance is extending the length and continuity of observational time series-especially in areas that are not well represented by the existing stream gauge network-observations in critical zones, and new observations to better understand snowpack, precipitation, evaporation, transpiration, sublimation, and how these processes are affected by land cover change (e.g., dust on snow, changing vegetation) and topography. The impacts of these changes are becoming better understood (e.g., Painter et al. 2010) and could be incorporated to help improve future simulations and adaptation planning.

vii) Strengthened connection with the management community: Our efforts as well as past studies (e.g., Waggoner 1990; AWWA 1997; Kirchhoff 2010; NRC 2010; and others) highlight the importance of sustained networks for connecting active research efforts and water resources practitioners (see supplementary text). Ongoing efforts allow scientists to engage with decision makers and gather feedback that can provide guidance for future priorities as science and adaptation progress. Better understanding how this can efficiently and effectively occur is an important line of research.

LESSON 7: As climate science evolves, our understanding of future uncertainties will continue to improve. However, the evidence indicates there is no single magic bullet that will "reduce uncertainties," nor will uncertainty ever be reduced to zero. Therefore, it is critical that both researchers and water managers redouble efforts and research to incorporate uncertainty and reconcile differences in future projections when possible. This will require continued communication and collaboration between the management 
and science communities, and will require scientists to more clearly articulate how their studies fit into existing knowledge and explain how and why their studies do or do not agree with past work.

\section{INTERPRETATIONS FOR DECISION}

MAKERS. While many studies over the last few years have projected future declines in Colorado River streamflows, the magnitude of the projected changes varies greatly. In response to our call for scientists to communicate more clearly with decision makers, we identify statements in which we have confidence, instead of just statements of uncertainty. These statements include implications for water resources planning and management based on multiple studies, which provide a path toward actionable science for decision makers. From our evaluation of past studies, we can say with high likelihood the following:

- Temperatures will rise in the Colorado River basin over the coming decades, as indicated by all GCMs used in AR4, for all emission scenarios.

- As indicated by most GCM projections for the Colorado River basin used in AR4 (more so than for most of the conterminous United States), precipitation will decline on an annual basis. Because the basin is at the nodal line of drying to the south and wetting to the north, there is a wide range in the projected magnitude of reductions (and a minority of GCMs that project increases) and results in future studies (e.g., AR5) may differ.

- The magnitude of temperature and precipitation response depends on the intensity of future human greenhouse gas emissions, with larger emissions resulting in larger increases in temperature and a greater likelihood of precipitation declines. AR4 estimates project temperature increases of $2.5^{\circ} \pm 1^{\circ} \mathrm{C}$ with $-4 \% \pm 12 \%$ changes in precipitation for high emissions scenarios and temperature increases of $2^{\circ} \pm 1^{\circ} \mathrm{C}$ with $-2.5 \% \pm 6 \%$ changes in precipitation for low emission scenarios by the mid-twenty-first century (Cayan et al. 2013).

- Warmer temperatures alone (ignoring possible changes in precipitation) will reduce annual runoff production in the Colorado River basin. For example, our evaluation of multiple hydrological models estimates streamflow declines of $6.5 \% \pm 3.5 \%{ }^{\circ} \mathrm{C}^{-1}$ at Lees Ferry. If we apply this to estimates of mid-twenty-first-century warming of $+2.5^{\circ} \pm 1^{\circ} \mathrm{C}$, then we estimate a future streamflow change that ranges approximately from $-5 \%$ to $-35 \%$.
- The ratio of annual runoff change to annual precipitation change (precipitation elasticity) at Lees Ferry is between about 2 and 3, based on our evaluation of multiple hydrological models and observations. This means that a $5 \%$ decline in precipitation will likely result in a $10 \%-15 \%$ decline in streamflow, in addition to the temperature-driven declines.

- The coarse spatial resolutions of current stateof-the-art GCMs and even RCMs do not resolve the scales of high-elevation hydrologic processes that dominate runoff production in the Colorado River basin. This necessitates downscaling and investigating future climate implications using offline hydrological model simulations.

- Natural variability in paleoclimate reconstructions clearly indicate that the modern climate can produce prolonged multidecadal dry periods (megadroughts). This type of drought, exacerbated by a steady reduction in flows due to ongoing climate change, would result in decades of sustained streamflows much lower than have been observed in approximately 100 years of instrumental record.

CONCLUSIONS. We have identified four major reasons for discrepancies in past projections of changes in Colorado River streamflow. In order of importance, these are differences in:

1) the GCMs and emission scenarios on which the climate scenarios are based;

2) the ability of the land surface and atmospheric models used to simulate properly the disproportionate contribution to Colorado River discharge of the relatively small high-elevation runoff source areas;

3) the sensitivities of the land surface hydrology models to precipitation and temperature changes; and

4) the methods used to statistically downscale (both spatially and temporally) the GCM scenarios.

Projections of future climate change impacts on Colorado River streamflow will always be uncertain, despite future research that will offer new insights, and may reduce uncertainty somewhat. It is thus important that water management decision making consider approaches that accommodate uncertainty and ambiguity of model evidence. It is also important that scientists more clearly articulate how their studies fit into the existing body of knowledge, explaining how and why their studies do or do not agree with past work. Scientists also need to reframe discussions when engaging decision makers to focus 
on certainties characterized by multiple studies and their implications for water resources planning and management.

Overall, the global simulations used in IPCC AR4 suggest substantial reductions in future Colorado River streamflow by the end of the twenty-first century due to a combination of strong temperature-induced runoff curtailment and a probable reduction in annual precipitation. An increasing number of climate model results for IPCC AR5 are now available (e.g., Seager et al. 2013) and will shed additional light on the nature of future Colorado River streamflow changes; the methods outlined herein provide a template for evaluation of the AR5 model implications, and should help to reduce uncertainty in their interpretation. In addition to this, paleoclimate reconstructions clearly indicate that there have been prolonged multidecadal dry periods that created megadroughts not seen in approximately 100 years of instrumental record. The superposition of such megadroughts on a continued trend of warming, and possible precipitation declines, should be viewed as the most realistic "worst case" scenarios for future planning.

ACKNOWLEDGMENTS. The authors thank Niklas Christensen, David Meko, James Prairie, Drew Peterson, Cody Routson, and Connie Woodhouse for their assistance, and numerous water managers for their encouragement to write a synthesis paper. We also thank Richard Seager from Lamont-Doherty Earth Observatory of Columbia University, Steve Markstrom from the U.S. Geological Survey, and three anonymous reviewers for their feedback. The research was funded by NOAA through its Regional Integrated Sciences and Assessments (RISA) cross-center project that included the California Nevada Applications Program (CNAP), the Climate Impacts Group (CIG), Climate Assessment for the Southwest (CLIMAS), and the Western Water Assessment (WWA) and NOAA's National Integrated Drought Information System. Additional support has been provided by the Climate Impacts Research Consortium (CIRC) RISA.

\section{REFERENCES}

Abatzoglou, J. T., and T. J. Brown, 2012: A comparison of statistical downscaling methods suited for wildfire applications. Int. J. Climatol., 32, 772-780, doi:10.1002/joc.2312.

Ault, T. R., J. E. Cole, and S. St. George, 2012: The amplitude of decadal to multidecadal variability in precipitation simulated by state-of-the-art climate models. Geophys. Res. Lett., 39, L21705, doi:10.1029/2012GL053424.
,,-- J. T. Overpeck, G. T. Pederson, S. St. George, B. Otto-Bliesner, C. A. Woodhouse, and C. Deser, 2013: The continuum of hydroclimate variability in western North America during the last millennium. J. Climate, 26, 5863-5878.

AWWA, 1997: Committee report-Climate change and water resources. J. Amer. Water Works Assoc., 89, 107-110.

Barnett, T. P., and D. W. Pierce, 2008: When will Lake Mead go dry? Water Resour. Res., 44, W03201, doi:10.1029/2007WR006704.

$\longrightarrow$, and — 2009: Sustainable water deliveries from the Colorado River in a changing climate. Proc. Natl. Acad. Sci. USA, 106, 7334-7338.

Behar, D., 2009: Testimony before the Subcommittee on Energy and Environment of the Committee on Science and Technology. Transcript, U.S. House of Representatives, $12 \mathrm{pp}$. [Available online at http:// docs.lib.noaa.gov/noaa_documents/National _Climate_Service_2009/Behar_Testimony.pdf.]

Brown, C., and R. L. Wilby, 2012: An alternate approach to assessing climate risks. Eos, Trans. Amer. Geophys. Union, 93, 401-402, doi:10.1029/2012EO410001.

Burges, S. J., 1991: Some aspects of hydrologic variability. Managing Water Resources in the West under Conditions of Climate Uncertainty: A Proceedings, National Academy Press, 275-280.

Burnash, R. J. C., R. L. Ferral, R. A. McGuire, and R. A. McGuire, 1973: A generalized streamflow simulation system: Conceptual models for digital computers. Joint Federal and State River Forecast Center, U.S. National Weather Service and California Department of Water Resources Tech. Rep., 204 pp.

Cayan, D. R., T. Das, D. W. Pierce, T. P. Barnett, M. Tyree, and A. Gershunov, 2010: Future dryness in the southwest US and the hydrology of the early 21st century drought. Proc. Natl. Acad. Sci. USA, 107, 21 271-21 276, doi:10.1073/pnas.0912391107.

— , and Coauthors, 2013: Future climate: Projected average. Assessment of Climate Change in the Southwest United States: A Report Prepared for the National Climate Assessment, G. Garfin et al. Eds., Southwest Climate Alliance Report, Island Press, 101-125.

Christensen, N. S., and D. P. Lettenmaier, 2007: A multimodel ensemble approach to assessment of climate change impacts on the hydrology and water resources of the Colorado River basin. Hydrol. Earth Syst. Sci., 3, 1-44.

—, A. W. Wood, N. Voisin, D. P. Lettenmaier, and R. N. Palmer, 2004: The effects of climate change on the hydrology and water resources of the Colorado River basin. Climatic Change, 62, 337-363. 
Conroy, J. L., J. T. Overpeck, J. E. Cole, and M. Steinitz-Kannan, 2009: Variable oceanic influences on western North American drought over the last 1200 years. Geophys. Res. Lett., 36, L17703, doi:10.1029/2009GL039558.

Cook, B. I., R. Seager, and R. L. Miller, 2011: On the causes and dynamics of the early twentieth-century North American pluvial. J. Climate, 24, 5043-5060.

Cook, E. R., C. A. Woodhouse, C. M. Eakin, D. M. Meko, and D. W. Stahle, 2004: Long-term aridity changes in the western United States. Science, 306, 1015-1018, doi:10.1126/science.1102586.

— , R. Seager, R. R. Heim Jr., R. S. Vose, C. Herweijer, and C. Woodhouse, 2010: Megadroughts in North America: Placing IPCC projections of hydroclimatic change in a long-term palaeoclimate context. J. Quat. Sci., 25, 48-61, doi:10.1002/jqs.1303.

— , and Coauthors, cited 2012: North American summer PDSI reconstructions, version 2a. IGBP PAGES/World Data Center Paleoclimatology Data Contribution Series 2008-046, NOAA/ NGDC Paleoclimatology Program. [Available online at ftp://ftp.ncdc.noaa.gov/pub/data/paleo /drought/NAmericanDroughtAtlas.v2/readme -NADAv2-2008.txt.]

Daly, C., R. P. Neilson, and D. L. Phillips, 1994: A statistical-topographic model for mapping climatological precipitation over mountainous terrain. J. Appl. Meteor., 33, 140-158.

Das, T., D. W. Pierce, D. R. Cayan, J. A. Vano, and D. P. Lettenmaier, 2011: The importance of warm season warming to western U.S. streamflow changes. Geophys. Res. Lett., 38, L23403, doi:10.1029/2011GL049660.

Deser, C., R. Knutti, S. Solomon, and A. S. Phillips, 2012: Communication of the role of natural variability in future North American climate. Nat. Climate Change, 2, 775-779, doi:10.1038/nclimate1562.

Diffenbaugh, N. S., 2005: Atmosphere-land cover feedbacks alter the response of surface temperature to $\mathrm{CO}_{2}$ forcing in the western United States. Climate Dyn., 24, 237-251.

Dominguez, F., E. Rivera, D. P. Lettenmaier, and C. L. Castro, 2012: Changes in winter precipitation extremes for the western United States under a warmer climate as simulated by regional climate models. Geophys. Res. Lett., 39, L05803, doi:10.1029/2011GL050762.

Emile-Geay, J., R. Seager, M. A. Cane, E. R. Cook, and G. H. Haug, 2008: Volcanoes and ENSO over the past millennium. J. Climate, 21, 3134-3148.

Fulp, T., 2005: How low can it go? Southwest Hydrol., 4 (2), 3 pp. [Available online at http://web.sahra.arizona .edu/swhydro/archive/V4_N2/SWHVol4Issue2.pdf.]
Gao, Y., J. A. Vano, C. Zhu, and D. P. Lettenmaier, 2011: Evaluating climate change over the Colorado River basin using regional climate models. J. Geophys. Res., 116, D13104, doi:10.1029/2010JD015278.

— , L. R. Leung, E. P. Salathé Jr., F. Dominguez, B. Nijssen, and D. P. Lettenmaier, 2012: Moisture flux convergence in regional and global climate models: Implications for droughts in the southwestern United States under climate change. Geophys. Res. Lett., 39, L09711, doi:10.1029/2012GL051560.

Graham, N. E., and Coauthors, 2007: Tropical Pacificmid-latitude teleconnections in medieval times. Climatic Change, 83, 241-285.

_, C. M. Ammann, D. Fleitmann, K. M. Cobb, and J. Luterbacher, 2011: Support for global climate reorganization during the "Medieval Climate Anomaly." Climate Dyn., 37, 1217-1245.

Haddeland, I., B. V. Matheussen, and D. P. Lettenmaier, 2002: Influence of spatial resolution on simulated streamflow in a macroscale hydrologic model. Water Resour. Res., 38, 1124-1133, doi:10.1029/2001WR000854.

Hamlet, A. F., and D. P. Lettenmaier, 2005: Production of temporally consistent gridded precipitation and temperature fields for the continental United States. J. Hydrometeor., 6, 330-336.

— E. P. Salathé, and P. Carrasco, 2010: Statistical downscaling techniques for global climate model simulations of temperature and precipitation with application to water resources planning studies. Final Rep. for the Columbia Basin Climate Change Scenarios Project, 27 pp. [Available online at www.hydro .washington.edu /2860/products/sites/r7climate /study_report/CBCCSP_chap4_gcm_final.pdf.]

Harding, B. L., A. W. Wood, and J. R. Prairie, 2012: The implications of climate change scenario selection for future streamflow projection in the upper Colorado River basin. Hydrol. Earth Syst. Sci. Discuss., 9, 847-894, doi:10.5194/hessd-9-847-2012.

Hartmann, H. C., 2005: Use of climate information in water resources management. Encyclopedia of Hydrological Sciences, M. G. Anderson, Ed., Vol. 5, John Wiley and Sons Ltd., 202.

Hidalgo, H. G., 2004: Climate precursors of multidecadal climate variability in the western United States. Water Resour. Res., 40, W12504, doi:10.1029/2004WR003350.

—, T. C. Piechota, and J. A. Dracup, 2000: Alternative principal components regression procedures for dendrohydrologic reconstructions. Water Resour. Res., 36, 3241-3249.

_-, M. D. Dettinger, and D. R. Cayan, 2008: Downscaling with constructed analogues: Daily precipitation 
and temperature fields over the United States. Pier Final Project Rep., California Energy Commission Tech. Rep. CEC-500-2007-123, 48 pp.

Hoerling, M., and J. K. Eischeid, 2007: Past peak water in the Southwest. Southwest Hydrol., 6 (1), 3 pp. [Available online at http://web.sahra.arizona.edu /swhydro/archive/V6_N1/feature2.pdf.]

— , D. P. Lettenmaier, D. Cayan, and B. Udall, 2009: Reconciling projections of Colorado River streamflow. Southwest Hydrol., 8 (3). [Available online at http://web.sahra.arizona.edu/swhydro/archive /V8_N3/feature2.pdf.]

Karnauskas, K. B., J. E. Smerdon, R. Seager, and J. F. González-Rouco, 2012: A Pacific centennial oscillation predicted by coupled GCMs. J. Climate, 25, 5943-5961.

Karpechko, A. Y., and E. Manzini, 2012: Stratospheric influence on tropospheric climate change in the Northern Hemisphere. J. Geophys. Res., 117, D05133, doi:10.1029/2011JD017036.

Kerr, R. A., 2011: Time to adapt to a warming world, but where's the science? Science, 334, 1052-1053.

Kirchhoff, C. J., 2010. Integrating science and policy: Climate change assessment and water resources management. Rep. CSS10-16, Center for Sustainable Systems, University of Michigan, $280 \mathrm{pp}$.

Knutti, R., and J. Sedláček, 2012: Robustness and uncertainties in the new CMIP5 climate model projections. Nat. Climate Change, 3, 369-373, doi:10.1038/NCLIMATE1716.

Livneh, B., P. J. Restrepo, and D. P. Lettenmaier, 2011: Development of a unified land model for prediction of surface hydrology and land-atmosphere interactions. J. Hydrometeor., 12, 1299-1320.

Mahmoud, M., and Coauthors, 2009: A formal framework for scenario development in support of environmental decision-making. Environ. Model. Software, 24, 798-808.

Maurer, E. P., A. W. Wood, J. C. Adam, D. P. Lettenmaier, and B. Nijssen, 2002: A long-term hydrologically based dataset of land surface fluxes and states for the conterminous United States. J. Climate, 15, 3237-3251.

— , H. G. Hidalgo, T. Das, M. D. Dettinger, and D. R. Cayan, 2010: The utility of daily large-scale climate data in the assessment of climate change impacts on daily streamflow in California. Hydrol. Earth Syst. Sci., 14, 1125-1138, doi:10.5194/hess-14-1125-2010.

McCabe, G. L., and S. L. Markstrom, 2007: A monthly water-balance model driven by a graphical user interface. U.S. Geological Survey Open-File Rep. 2007-1088, 6 pp.

— , and D. M. Wolock, 2007: Warming may create substantial water supply shortages in the Colorado
River basin. Geophys. Res. Lett., 34, L22708, doi:10.1029/2007GL031764.

— , and — , 2011: Century-scale variability in global annual runoff examined using a water balance model. Int. J. Climatol., 31, 1739-1748, doi:10.1002/ joc. 2198 .

Mearns, L. O., and Coauthors, 2012: The North American Regional Climate Change Assessment Program: Overview of phase I results. Bull. Amer. Meteor. Soc., 93, 1337-1362.

Meko, D. M., C. A. Woodhouse, C. H. Baisan, T. Knight, J. J. Lukas, M. K. Hughes, and W. Salzer, 2007: Medieval drought in the upper Colorado River basin. Geophys. Res. Lett., 34, L10705, doi:10.1029/2007GL029988.

$-,-,-,-\longrightarrow,-$, and - , cited 2012: Upper Colorado River flow reconstruction. IGBP PAGES/World Data Center for Paleoclimatology Data Contribution Series 2007-052. NOAA/NCDC Paleoclimatology Program. [Available online at ftp://ftp.ncdc.noaa.gov/pub/data/paleo/treering /reconstructions/northamerica/usa/upper-colorado -flow2007.txt.]

Milly, P. C. D., K. A. Dunne, and A. V. Vecchia, 2005: Global pattern of trends in streamflow and water availability in a changing climate. Nature, 438, 347-350.

—, J. Betancourt, M. Falkenmark, R. Hirsch, Z. Kundzewicz, D. Lettenmaier, and R. Stouffer, 2008: Stationarity is dead: Whither water management? Science, 319, 573-574.

Moss, R. H., and Coauthors, 2010: The next generation of scenarios for climate change research and assessment. Nature, 463, 747-756, doi:10.1038/ nature08823.

Mote, P. W., L. D. Brekke, P. B. Duffy, and E. Maurer, 2011: Guidelines for constructing climate scenarios. Eos, Trans. Amer. Geophys. Union, 92, 257-258.

Nakicenovic, N., and R. Swart, Eds., 2000: Special Report on Emissions Scenarios. Cambridge University Press, 599 pp.

Nash, L. L., and P. H. Gleick, 1991: The sensitivity of streamflow in the Colorado basin to climatic changes. J. Hydrol., 125, 221-241.

Niu, G. Y., and Coauthors, 2011: The community Noah land surface model with multiparameterization options (Noah-MP): 1. Model description and evaluation with local-scale measurements. J. Geophys. Res., 116, D12109, doi:10.1029/2010JD015139.

NRC, 2010: Informing an Effective Response to Climate Change. National Academies Press, 348 pp.

- , 2011: Climate Stabilization Targets: Emissions, Concentrations, and Impacts over Decades to Millennia. National Academies Press, 298 pp. 
Oglesby, R., S. Feng, Q. Hu, and C. Rowe, 2012: The role of the Atlantic multidecadal oscillation on medieval drought in North America: Synthesizing results from proxy data and climate models. Global Planet. Change, 84, 56-65.

Overpeck, J., and B. Udall, 2010: Dry times ahead. Science, 328, 1642-1643, doi:10.1126/science.1186591.

Painter, T. H., J. S. Deems, J. Belnap, A. F. Hamlet, C. C. Landry, and B. Udall, 2010: Response of Colorado River runoff to dust radiative forcing in snow. Proc. Natl. Acad. Sci. USA, 107, 17 125-17 130.

Pederson, G. T., and Coauthors, 2011: The unusual nature of recent snowpack declines in the North American Cordillera. Science, 333, 332-335, doi:10.1126/science.1201570.

Racherla, P. N., D. T. Shindell, and G. S. Faluvegi, 2012: The added value to global model projections of climate change by dynamical downscaling: A case study over the continental U.S. using the GISS-ModelE2 and WRF models. J. Geophys. Res., 117, D20118, doi:10.1029/2012JD018091.

Rasmussen, R., and Coauthors, 2011: High-resolution coupled climate runoff simulations of seasonal snowfall over Colorado: A process study of current and warmer climate. J. Climate, 24, 3015-3048.

Rauscher, S. A., J. S. Pal, N. S. Diffenbaugh, and M. M. Benedetti, 2008: Future changes in snowmelt-driven runoff timing over the western US. Geophys. Res. Lett., 35, L16703, doi:10.1029/2008GL034424.

Routson, C. C., C. A. Woodhouse, and J. T. Overpeck, 2011: Second century megadrought in the Rio Grande headwaters, Colorado: How unusual was medieval drought? Geophys. Res. Lett., 38, L22703, doi:10.1029/2011GL050015.

Salas, J. D., 1993: Analysis and modelling of hydrologic time series. Handbook of Hydrology, D. R. Maidment, Ed., Mc-Graw-Hill, Inc., 19.1-19.72.

Scaife, A. A., and Coauthors, 2012: Climate change projections and stratosphere-troposphere interaction. Climate Dyn., 38, 2089-2097.

Seager, R., and G. A. Vecchi, 2010: Greenhouse warming and the 21st century hydroclimate of southwestern North America. Proc. Natl. Acad. Sci. USA, 107, 21 277-21 282, doi:10.1073/pnas.0910856107.

— imminent transition to a more arid climate in southwestern North America. Science, 316, 1181-1184.

—, R. Burgman, Y. Kushnir, A. Clement, E. Cook, N. Naik, and J. Miller, 2008: Tropical Pacific forcing of North American medieval megadroughts: Testing the concept with an atmosphere model forced by coral-reconstructed SSTs. J. Climate, 21, 6175-6190.
—, M. Ting, C. Li, N. Naik, B. Cook, J. Nakamura, and H. Liu, 2013: Projections of declining surfacewater availability for the southwestern United States. Nat. Climate Change, 3, 482-486, doi:10.1038/ NCLIMATE1787.

Stockton, C. W., and G. C. Jacoby Jr., 1976: Long-term surface-water supply and streamflow trends in the upper Colorado River basin. Lake Powell Research Project Bull. 18, National Science Foundation, 70 pp.

Tang, Q., and D. P. Lettenmaier, 2012: 21st century runoff sensitivities of major global river basins. Geophys. Res. Lett., 39, L06403, doi:10.1029/2011GL050834.

Trenberth, K. E., 1998: Atmospheric moisture residence times and cycling: Implications for rainfall rates and climate change. Climatic Change, 39, 667-694.

USBR, 2007a: Appendix A: CRSS model documentation. Final Environmental Impact Statement-Colorado River interim guidelines for lower basin shortages and coordinated operations for Lake Powell and Lake Mead. [Available online at www.usbr.gov/lc/region /programs/strategies/FEIS/AppA.pdf.]

— , 2007b: Colorado River interim guidelines for lower basin shortages and coordinated operations for Lakes Powell and Mead. Draft Environmental Impact Statement, U.S. Department of the Interior, Boulder City, Nevada. [Available online at www.usbr.gov/lc /region/programs/strategies/draftEIS/index.html.]

_ , 2011a: Colorado River basin water supply and demand study. Tech. Rep. B, U.S. Department of the Interior, Boulder City, Nevada. [Available online at www.usbr.gov/lc/region/programs/crbstudy /finalreport/index.html.]

— , 2011b: West-wide climate risk assessments: Bias-corrected and spatially downscaled surface water projections. Tech. Memo. 86-68210-201101 , U.S. Department of the Interior, Denver, Colorado, 122 pp. [Available online at www.usbr .gov/WaterSMART/docs/west-wide-climate-risk -assessments.pdf.]

— [Available online at www.usbr.gov/lc/region/g4000 /NaturalFlow/current.html.]

Vano, J. A., T. Das, and D. P. Lettenmaier, 2012: Hydrologic sensitivities of Colorado River runoff to changes in precipitation and temperature. J. Hydrometeor., 13, 932-949.

Waggoner, P. E., Ed., 1990: Climate change and US water resources. Wiley, $496 \mathrm{pp}$.

Wi, S., F. Dominguez, M. Durcik, J. Valdes, H. F. Diaz, and C. L. Castro, 2012: Climate change projection of snowfall in the Colorado River basin using dynamical downscaling. Water Resour. Res., 48, W05504, doi:10.1029/2011WR010674. 
Wood, A. W., and D. P. Lettenmaier, 2006: A test bed for new seasonal hydrologic forecasting approaches in the western United States. Bull. Amer. Meteor. Soc., 87, 1699-1712.

— , L. R. Leung, V. Sridhar, and D. P. Lettenmaier, 2004: Hydrologic implications of dynamical and statistical approaches to downscaling climate model outputs. Climatic Change, 62, 189-216.

Woodhouse, C. A., and J. T. Overpeck, 1998: 2000 years of drought variability in the central United States. Bull. Amer. Meteor. Soc., 79, 2693-2714.

— Great Plains drought. Tree-Ring Res., 57, 89-103.
- and J. J. Lukas, 2006: Multi-century tree-ring reconstructions of Colorado streamflow for water resource planning. Climatic Change, 78, 293-315.

—, S. T. Gray, and D. M. Meko, 2006: Updated streamflow reconstructions for the upper Colorado River basin. Water Resour. Res., 42, W05415, doi:10.1029/2005WR004455.

, D. M. Meko, G. M. MacDonald, D. W. Stahle, and E. R. Cook, 2010: A 1,200-year perspective of 21st century drought in the southwestern North America. Proc. Natl. Acad. Sci. USA, 107, $21283-21288$, doi:10.1073/pnas.0911197107.

\section{THE LIFE CyCLES OF EXTRATROPICAL CYCLONES}

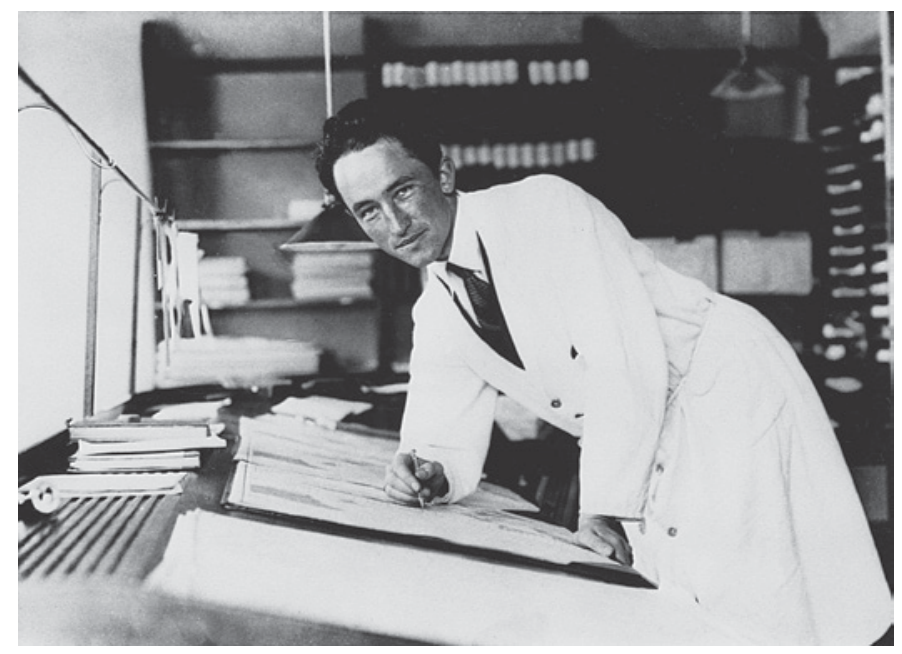

\section{Edited by Melvyn A. Shapiro and Sigbjørn Grønås}

Containing expanded versions of the invited papers presented at the International Symposium on the Life Cycles of Extratropical Cyclones, held in Bergen, Norway, 27 June-1 July 1994, this monograph will be of interest to historians of meteorology, researchers, and forecasters. The symposium coincided with the 75th anniversary of the introduction of Jack Bjerknes's frontal-cyclone model presented in his seminal article, "On the Structure of Moving Cyclones." The monograph's content ranges from a historical overview of extratropical cyclone research and forecasting from the early eighteenth century into the mid-twentieth century, to a presentations and reviews of contemporary research on the theory, observations, analysis, diagnosis, and prediction of extratropical cyclones. The material is appropriate for teaching courses in advanced undergraduate and graduate meteorology.

The Life Cycles of Extratropical Cyclones is available for $\mathbf{\$ 7 5}$ list/\$55 members.

To order, visit www.ametsoc.org/amsbookstore, or see the order form at the back of this issue. 